\title{
La influencia del tipo circadiano, la hora del día y la dificultad de la clase sobre las notas de los estudiantes
}

\author{
Todd McElroy y Lynn Mosteller
}

Dpto. de Psicología, Appalachian State University, Boone, Carolina del Norte

EE.UU.

mcelroygt@appstate.edu 


\section{Resumen}

Introducción. Este trabajo investiga en qué se ven afectadas las notas de los alumnos a causa de diferencias individuales en el ritmo circadiano, la hora de la clase, y la dificultad de la misma.

Método. Con una muestra de estudiantes universitarios, les valoramos por tipo de personalidad con horas óptimas por la mañana o por la tarde-noche, y luego recogemos de ellos su recuerdo de clases ya cursadas, así como estas clases y sus notas según se reflejan en el registro oficial de la universidad.

Resultados y Conclusiones. Los resultados de nuestros análisis indican que, para las clases muy difíciles, "hora-óptima-del-dia" es un factor determinante en las notas de los alumnos. Nuestros resultados también sugieren que los alumnos con horas óptimas por la tarde-noche son los más afectados por el horario normal de las clases. Análisis de nuestros hallazgos también revela efectos de hora-óptima-del-día para el recuerdo de las clases del semestre anterior. Además de las implicaciones obvias para los estudiantes, se comentan también implicaciones para profesores y administradores universitarios. 